DOI 10.37882/2223-2982.2020.08-2.18

\title{
ПОНЯТИЕ «КОНЦЕПТ» В СОВРЕМЕННОЙ ЛИНГВИСТИКЕ И СМЕЖНЫХ ОБЛАСТЯХ ЗНАНИЯ
}

\section{THE TERM «KONTSEPT» IN MODERN LINGUISTICS AND RELATED FIELDS OF KNOWLEDGE}

S. Trotciuk

Summary: The article reveals the content of the concept «concept», which is becoming more and more widespread in linguistics and psycholinguistics. The article presents different points of view on the definition of the term "concept» and the scope of its use. Particular attention is paid to the study of knowledge used in the course of language communication, which is considered one of the leading aspects of cognitive linguistics. The question of the role of conceptualization in human cognition is one of the Central issues of modern cognitive linguistics.

Keywords: concept, conceptualization, cognitive linguistics, cultural linguistics, cognition.
K ак показывает анализ научной литературы, в современном языкознании термин концепт не имеет единого толкования, но можно выделить три основных подхода к его изучению: лингвокогнитивный $[1 ; 19 ; 5 ; 12 ; 14 ; 24]$ и др.; лингвокультурологический или концептуально-культурологический (термин Ю.Д. Тильман) [29; 28; 30; 10; 21] и др.); логический [3; 22] и др.

В русистике появление термина концепт связывают с именем С.А. Аскольдова-Алексеева, развивающего когнитивно-психологическую точку зрения на природу концепта. Согласно этой точке зрения концепт является свернутым первичным мыслительным представлением, замещая собой в речи одно из значений слова. В $[36$, р. 1552] концепт также определяется как «важное ментально-абстрактное представление». Его авторы-составители считают, что индивидуальные представления носят субъективный характер и отражают внешние связи предметов, бросающиеся в глаза и играющие важную роль в жизни человека, а концепты, складываясь из совокупности этих представлений в коллективном сознании, отражают сущностные характеристики предметов и тем самым обеспечивают объективность знания [36, р. 1555].

Активно теоретические подходы к осмыслению концепта, которые можно обозначить одним составным термином - когнитивная лингвистика, разрабатываются с начала последней трети XX века. Ещё сравнительно

\author{
троцюк Светлана Николаевна \\ к.филол.н., дочент, Российский государственный \\ гидрометеорологический университет \\ svetlana.trocuk@mail.ru
}

Аннотация: Статья раскрывает содержание понятия «концепт», которое получает все более широкое распространение в лингвистике и психолингвистике. В статье приводятся разные точки зрения на определение термина «концепт» и сферы его использования. Особое внимание уделяется изучению знаний, используемых в ходе языкового общения, которое считается одним из ведущих аспектов когнитивной лингвистики. Вопрос о роли концептуализации в человеческом познании является одним из центральных вопросов современной когнитивной лингвистики.

Ключевые слова: концепт, концептуализация, когнитивная лингвистика, лингвокультурология, когниция.

недавно в лингвистике считалось вполне приемлемым рассматривать естественный язык в качестве некой абстрактной сущности, как если бы он не являлся частью нашей истории. Многие исследователи придерживались позиции, согласно которой существует жесткое разграничение между языковой компетенцией и употреблением языка. Но языковая система - это лишь небольшая часть того целостного явления, которое учёные стремятся познать.

Участвуя в актах коммуникации, человек либо воспринимает то, что говорят или пишут другие, либо сам порождает высказывание. В первом случае его действительной целью является понимание мыслей, выражаемых с помощью языка как средства их передачи. Однако знания, используемые при декодировании высказывания, отнюдь не ограничиваются сведениями о языке. Сюда входит также информация о мире, социуме, речевой ситуации и многом другом. При этом ни один из упомянутых типов информации не является единственно достаточным для возникновения понимания. Только изучение способов взаимодействия и организации всех типов знания приближает к пониманию сути языковой коммуникации.

Изучение знаний, используемых в ходе языкового общения, считается одним из ведущих аспектов когнитивной лингвистики. Кроме того, данное направление науки о языке занимается анализом связи языковых процессов с познавательной деятельностью человека, с 
актами концептуализации и категоризации.

Вопрос о роли концептуализации в человеческом познании является одним из центральных вопросов современной когнитивной лингвистики. Этой проблеме посвящены работы ведущих зарубежных и отечественных когнитивистов: Н. Ф. Алефиренко [1], Н.Н. Болдырева [7], Е.С. Кубряковой [15; 16], Дж. Лакоффа [17], Н.В. Сафоновой [26], Т.А. Фесенко [31] и мн. др. Концептуализация - это осмысление поступающей информации, мысленное конструирование предметов и явлений, которое приводит к образованию определённых коллективных представлений о мире в виде концептов как смыслов, фиксированных в сознании людей. Например, в сознании человека может сформироваться концепт дома, вечности, движения и т.д. [15, с. 10-34]. Категоризация это деление мира на категории и отнесение конкретных предметов и событий к этим категориям. Она является важнейшей функцией мышления, лежащей в основе всей познавательной деятельности человека, и направлена на объединение сходных или тождественных единиц в более крупные разряды.

Таким образом, когнитивная лингвистика имеет своим предметом исследование слов, фразеологических единиц, высказываний и текстов, репрезентирующих в языке и речи определённые абстрактные понятия, базирующиеся на образных ассоциациях.

Однако в первую очередь когнитивная лингвистика занимается когницией. Когниция - понятие, которое охватывает не только целенаправленное, теоретическое познание, но и простое, обыденное (не всегда осознанное) постижение мира в каждодневной жизни человека, приобретение самого простого - телесного, чувственнонаглядного, сенсорно-моторного - опыта в повседневном взаимодействии человека с окружающим миром. Е.С. Кубрякова ссылается на мнение Ж. Фоконье, который отмечает, что «начинания когнитивной лингвистики (the cognitive linguistics enterprise) уже были поразительно успешными. Не будет преувеличением сказать, что, пожалуй, впервые здесь была обоснована подлинная наука о конструировании значения и его динамике. Это было достигнуто благодаря интенсивному изучению и моделированию когниции, лежащей за языком и преодолевающей его пределы, но в то же время в определённом виде отраженной в языке» [15, с. 31]. По мнению Н.Н. Болдырева, «концепт является результатом когниции, связанной с получением информации, знаний, их преобразованием, запоминанием, извлечением из памяти, использованием» [7, с. 24]. М.А. Холодная, объединяя все составляющие когнитивной лингвистики - концептуализацию, категоризацию и когницию, понимает под концептом «познавательную психическую структуру, особенности организации которой обеспечивают возможность отражения действительности в единстве раз- нокачественных аспектов» [34, с. 20].

Основатели когнитивной лингвистики Дж. Лакофф и М. Джонсон, характеризуя открытия когнитивистики и её главные достижения, указывают на три обстоятельства: 1) «понятийная система играет центральную роль в определении повседневных реальностей»; 2) «понятийная система не относится к числу того, что мы обычно осознаём»; 3) «бо́льшая часть нашей обыденной понятийной системы в сущности своей метафорична» [18, с. 126-127]. Представляется, что формулирование этих трёх тезисов обозначило новую ступень в постижении способов, закономерностей и особенностей взаимодействия языка, мышления и культуры, а следовательно, и новые аспекты взаимодействия лингвистики, когнитологии, культурологии, философии; расширило рамки содержательного анализа языковых явлений, придало значительно большую глубину и эффективность семантическим исследованиям и привело к широкому использованию в лингвистических исследованиях базового термина современной когнитивистики - термина концепт $[15$, с. 31$]$.

При лингвокогнитивном подходе, в котором семантика слова соотносится со всем объёмом знаний об обозначаемом, концепт рассматривается в рамках понятий знания и сознания и понимается как ментальное образование, своеобразный фокус знаний о мире, сочетающий в себе свойства понятия и представления, когнитивная структура, включающая разносубстратные единицы оперативного сознания. В интерпретации такого рода на первый план выступает проблема соотношения языка и сознания, а как следствие - вопрос о соотношении терминов концепт и понятие. Это закономерно, так как термин концепт пришёл в лингвистику из логики, где он воспринимается как синоним термина понятие: «Концепт (от лат. conceptus - понятие) - целостная совокупность представлений о свойствах объекта. В соответствии со сложившей традицией в естественном языке под концептом понимается то абстрактное содержание, понимание которого является необходимым условием адекватного употребления данного имени. Различные имена могут обозначать один и тот же объект и при этом выражать абстрактное содержание, но не наоборот». Таким образом, в традиционной лингвистике концепт трактовался как «мысль, отражающая в обобщённой форме предметы и явления посредством фиксации их свойств и отношений» [8, с. 383].

По мнению С.А. Аскольдова-Алексеева, как уже говорилось, самой существенной стороной концепта выступает функция заместительства. Концепт, в его понимании, «мысленное образование, которое замещает нам в процессе мысли неопределённое множество предметов одного и того же рода» [4, с. 28]. Некоторые концепты можно рассматривать как схематические представле- 
ния, лишенные тех или иных конкретных деталей. Понятие же, как считает исследователь, это «прежде всего точка зрения на ту или иную множественность представлений и затем готовность к их мысленной обработке с этой точки зрения» [там же, с. 30].

Э. Сепир ставит понятие в один ряд с психологическими терминами восприятие и впечатление, так как оно является результатом многочисленных регистраций человеком действительности и открыто для дополнительных коммуникаций. Более того, учёный сравнивает понятие с некоторым комплексом мысли, удобным для перекодировки в речевую деятельность [27, с. 34].

В «Философском энциклопедическом словаре» словарная статья «Концепт» отсутствует, а понятие трактуется как «одна из логических форм мышления в противоположность суждению и умозаключению, которые состоят из понятий» [32, с. 354]. Проводится граница между понятиями, которыми «мы пользуемся в повседневной жизни», и понятиями логики [там же]. Отмечается, что в мышлении народа или отдельного человека «понятия образуются не путем восприятия и объединения в понятии присущих группе предметов одинаковых признаков, а благодаря тому, что сначала воспринимаются и перерабатываются в понятия существенные свойства вещей ... и что эти немногие, широкие, но нечеткие понятия лишь постепенно начинают подразделяться на многочисленные, узкие и резко разграниченные понятия, ибо в сфере данного познается прегнантное (могущее появиться - С.Т.), точно так же, как и все увеличивающееся количество ступеней, ведущих к прегнантности или от неё» [там же].

А.П. Бабушкин понимает концепт как «ментальную репрезентацию, которая определяет, как вещи связаны между собой» [5, с. 16].

Исследователь считает возможным охарактеризовать понятие как логически конструируемый концепт без образности. В отличие от него представления об игрушке, красоте и пр. имеют образный уровень, о чем свидетельствует наличие так называемых прототипов (см. ниже). Понятие - концепт, который состоит из наиболее общих, существенных признаков предмета или явления, это результат их рационального отражения и осмысления.

Не все учёные считают возможным воспринимать понятие как своеобразный тип концепта. По мнению Л.О. Чернейко и В.А. Долинского, содержание концепта включает в себя содержание понятия, но не исчерпывается им, поскольку охватывает всё множество коннотативных элементов имени, проявляющихся в его сочетаемости. При этом обращается внимание на то, что в отличие от сублогической основы концепта фундамент любого понятия (наивного и научного) определяется как «логический, рациональный». В отношении научного понятия замечается, что содержание его «расширяется за счет включения тех свойств явления, которые открылись научному знанию» [35, с. 21-22].

Н.Н. Болдырев определяет понятие как «рациональный, логически осмысленный концепт, отражающий наиболее общие, существенные (логически конструируемые) признаки предмета или явления» [7, с. 24], между тем как концепт иного типа в его понимании может отражать любые, не обязательно существенные признаки объекта.

В европейской лингвистике концепт трактуется в рамках теории языка специальных целей. В. Смит отмечает, что концепт следует понимать как квант знания: «а concept should be understood as an the portion of knowledge basic to our perception of a given fragment of reality as an individual object» [38, с. 2]. Г. Пихт рассматривает концепт в качестве «единицы мысли, знания и познания» («а unit of thought, knowledge and cognition») $[37$, c. 7].

Е.С. Кубрякова полагает, что концепт является «оперативной единицей памяти, ментального лексикона, концептуальной системы и языка мозга, всей картины мира, кванта знания» [14, с. 91-92], а процесс концептуализации направлен в общем на «выделение неких предельных для определённого уровня рассмотрения единиц (концептов) человеческого опыта в их идеальном содержательном представлении» [16, с. 318].

Концепты и понятия как лингвокогнитивные явления «рождаются в процессе восприятия мира, создаются в актах познания, отражают и обобщают человеческий опыт в разных типах деятельности» [16, с. 57]. Соединяться могут как признаки, отражающие реально наличествующие элементы действительности, так и признаки, отражающие элементы действительности, существующие в отдельности, но не обнаруживаемые в том или ином конкретном сочетании. В последнем случае есть концепт, но нет в природе самих предметов, нет референтов у соответствующих слов, хотя чувственные образы, отражающие реально существующие признаки, налицо. Следовательно, концепт - это продукт отражения действительности, но продукт, обработанный в результате мыслительной деятельности.

Р.М. Фрумкина, стоя на позициях психолингвистики, характеризует концепт скорее как индивидуализированное представление, чем как понятие: «... не только разные языки "концептуализируют", то есть преломляют действительность по-разному, но за одним и тем же словом данного языка в сознании разных людей могут стоять разные концепты» [33, с. 3]. 
3.Д. Попова и И.А. Стернин считают, что концепт - это «комплексная мыслительная единица, актуализирующая в процессе мыслительной деятельности свои различные признаки и слои» [23, с. 37].

Аналогичный взгляд высказывает и С.В. Ракитина, которая характеризует концепт как «совокупность смыслов в сознании конкретного человека. По мнению этого учёного, в процессе функционирования концепта в познавательной деятельности индивида могут проявляться не все составляющие его признаки, а лишь актуальные в данном контексте, в данной речевой ситуации. Понятие же, являясь продуктом научного мышления, длительного процесса развития познания, предполагает высокую степень обобщения, четкости, объективности, ясности, отсутствия эмоциональности [25, с. 81$]$.

В применении термина концепт к семантике слов, не относящихся к числу специально создаваемых для обозначения точных понятий (то есть элементов терминосистем), удачным кажется уточнение, с помощью которого корректирует значение термина понятие при использовании его для характеристики концепта Н.Д. Арутюнова, - «человеческое понятие» [3, с. 142]. Понятие и концепт как мыслительные образования, репрезентированные в сознании языковыми знаками, являются соотносимыми, но не равнозначными.

По мнению Н.Ф. Алефиренко, «будучи элементами сознания, понятие (conceptus) и концепт (conceptum) служат смысловым и конструктивным ядром любого концептуального пространства (концептосферы, концептуальной парадигмы текста), в том числе и языкового сознания» $[2$, с. 91].

Ю.С. Степанов подчёркивает, что концепт и понятие являются терминами разных наук: понятие употребляется главным образом в философии и логике, а концепт, изначально являясь термином математической логики, закрепился последнее время в науке о культуре - культурологии [28, с. 40]. В отличие от понятия, в смысловом строе концепта Ю.С. Степанов выделяет «три компонента или три слоя»: 1) «основной, актуальный признак; 2) дополнительный или несколько дополнительных, "пассивных" признаков, являющихся уже не актуальными, "историческими"; 3) внутреннюю форму, обычно вовсе не осознаваемую, запечатлённую во внешней, словесной форме» [28, с. 45].

Термин концепт, соотносимый (но не отождествляемый) с понятийным феноменом, в дальнейшем все более и более приобретает лингвокультурологическое наполнение, то есть концепт понимается как ментальное образование, обладающее лингвистической и культурологической спецификой. Концепт предстаёт как культурно-информационная единица, созданная в про- цессе редуцирования результатов опытного познания действительности до объёмов, которые способна удержать человеческая память, и соотнесённая с культурноценностными доминантами, выраженными в религии, идеологии, искусстве, науке.

С этим связано, на наш взгляд, наличие таких его терминологических аналогов, как лингвокультурема [11], логоэпистема [13], мифологема [6], образ-архетип [1], ключевое слово [9] и др.

Лингвокультурология - научная дисциплина синтезирующего типа - исследует взаимодействие языка и культуры, языка и этноса, языка и менталитета в процессе их функционирования. Неоспорима значимость лингвокультурологии как комплексной области научного знания о взаимосвязи и взаимовлиянии языка и культуры, где язык - это «средство концентрированного осмысления коллективного опыта, который закодирован во всем богатстве значений слов, фразеологических единиц, общественных текстов, формульных этикетных ситуаций» [21, с. 6].

Потенциальная задача лингвокультурологии состоит в том, чтобы «эксплицировать культурную значимость языковой единицы (то есть "культурные знания") на основе соотнесения языковой единицы с кодами культуры» [20].

Культурологическая теория концепта рассматривает его как противоречивую единицу, обладающую динамической природой и при этом характеризующуюся стереотипностью и константностью.

Как внутри одной системы, так и между ними происходит своеобразная диффузия культурных концептов. Некоторые концепты втягиваются в область культуры и пребывают в ней на протяжении длительного времени. Именно их Ю.С. Степанов обозначает термином константы: «Константа в культуре - это концепт, существующий постоянно или, по крайней мере, очень долгое время» [28, с. 84]. В то же время другие концепты постепенно выходят из сферы активного функционирования.

Термин «концепт» активно входит в терминологическую систему современной гуманитарной науки. Этот процесс происходит одновременно в нескольких направлениях. Первое направление связано с «обживанием» концептом своего теоретического пространства - поиском дефиниций понятия и осуществлением типологизации концептов, второе - с порождением собственных дериватов, появлением слов и сочетаний типа концептосфера (Д.С. Лихачев), концептуализированная предметная область (Ю.С. Степанов, С.Е. Никитина), концептуальный фон (Н.Д. Арутюнова), концептуальная парадигма (Л.Б. Савенкова). 
В соответствии с двумя основными функциями человеческого сознания, воспринимающего внеязыковую действительность, - 1) различать в ней отдельные элементы и 2) выделять в их кругу более и менее значимые, важные - формируемые в сознании концепты можно разделить на два вида: констатирующие и ценностные. На наш взгляд, это разделение является основанием для лингвокультурологического представления концепта.
Таким образом, концепт рождается как единица универсального предметного кода, которая и остается его ядром. Ядро постоянно окутывается, обволакивается новыми слоями концептуальных признаков, что увеличивает объём концепта и насыщает его содержание, в плане выражения это воплощается в том, что сведения о концепте можно извлекать не из одного языкового знака, а из значительной их совокупности, образующей сложную лингвистическую концептуальную парадигму.

\section{ЛИТЕРАТУРА}

1. Алефиренко Н.Ф. Поэтическая энергия слова. Синергетика языка, сознания и культуры. М.: Academia, 2002. 394 с.

2. Алефиренко Н.Ф. Синергетика культурного концепта и знака в системе языка и текстах // Культурные концепты в языке и тексте. Белгород: Изд-во Белгородского госуниверситета, 2005. С. 9-13.

3. Арутюнова Н.Д. Типы языковых значений: Оценка. Событие. Факт. М.: Наука, 1988. 338 с.

4. Аскольдов-Алексеев С.А. Концепт и слово // Русская речь. Новая серия. - 1928. - Вып. 2. - С. 28-44.

5. Бабушкин А.П. Типы концептов в лексико-фразеологической семантике языка. Воронеж: Изд-во ВГУ, 1996. 103 с.

6. Базылев В.Н. Мифологема скуки в русской культуре (И. А. Гончаров «Обыкновенная история»). М.: Academia, 1999. С. 130-147.

7. Болдырев Н.Н. Концепт и языковое значение. Лексические и грамматические концепты // Когнитивная семантика. Тамбов: Изд-Во ТГУ, 2000. С. 24.

8. Большая энциклопедия современного русского языка. Под ред. В.И. Ивановой. М.: Большая российская энциклопедия, 1998. 4650 c.

9. Вежбицкая А. Язык. Культура. Познание. М.: Русская словесность, 1996. 411 с.

10. Воркачёв С.Г. Концепт счастья в русском языковом сознании: опыт лингвокультурологического анализа. Краснодар: КубГТУ, 2002.140 с.

11. Воробьёв В.В. Лингвокультурология (теория и методы): Монография. М.: Изд-во РУДН, 1997. 331 с.

12. Карасик В.И. Языковой круг: Личность. Концепты. Дискурс. Волгоград: Перемена, 2002.477 с.

13. Костомаров В.Г. Современный русский язык и культурная память // Этнокультурная специфика речевой деятельности: Сб. обзоров. М.: ИНИОН РАН, 2000. C. 23-36.

14. Кубрякова Е.С. Краткий словарь когнитивных терминов. М.: МГУ им. Ломоносова, 1996. 245 с.

15. Кубрякова Е.С. Размышления о судьбах когнитивной лингвистики на рубеже веков // Вопросы филологии. 2001. № 1. С. 10-34.

16. Кубрякова Е.С. Язык и знание: на пути получения знаний о языке: Части речи с когнитивной точки зрения. Роль языка в познании мира. М.: Языки славянской культуры, 2004. 555 с.

17. Лакофф Дж. Лингвистические гештальты // Новое в зарубежной лингвистике. М.: Прогресс, 1981. С. 350-368.

18. Лакофф Дж. Метафоры, которыми мы живём // Язык и моделирование социального взаимодействия: сб. Статей / Общ. Ред. В. В. Петрова. М.: Прогресс, 1987. С. 126-170.

19. Лихачёв Д.С. Концептосфера русского языка // Известия АН СССР. Серия литература и язык. Т. 52. 1993. № 1. С. 4-8.

20. Маслова В.А. Когнитивная лингвистика: учеб. пособие. 2-е изд. Минск: ТетраСистемс, 2005. 256 с.

21. Мокаева И.Р. Этические концепты в языковой картине мира (на материале русского и карачаево-балкарского языков): автореф. дис. . . канд. филол. наук: 10.02.19. Нальчик, 2004. 15 с.

22. Павилёнис Р.И. Проблема смысла: Современный логико-философский анализ языка. М.: Мысль, 1983. 286 с.

23. Попова 3.Д. Очерки по когнитивной лингвистике. Воронеж: Истоки, 2001. 192 с.

24. Попова 3.Д. Понятие «концепт» в лингвистических исследованиях. Воронеж: Воронежский госуниверситет, 1999.30 c.

25. Ракитина С.В. Концепт и понятие как смыслообразующие единицы научного текста // Культурные концепты в языке и тексте. Белгород: изд-во Белгородского госуниверситета, 2005. С. 79-85.

26. Сафонова Н.В. Концепт благо/добро как сегмент ментального поля нации (на материале русского языка). Тамбов: Изд-во Тамбовского госуниверситета, 2003. 357 C.

27. Сепир Э. Избранные труды по языкознанию и культурологи. М.: Издательская группа «Прогресс» «ниверс», 1993. 656 с.

28. Степанов Ю.С. Константы: словарь русской культуры. Опыт исследования. М.: Школа «Языки русской культуры», 1997. 824 с.

29. Телия В.Н. Русская фразеология. Семантический, прагматический и лингвокультурологический аспекты. М.: Школа «Языки русской культуры», 1996.288 с.

30. Тильман Ю.Д. Культурные концепты в языковой картине мира (поэзия Ф. И. Тютчева): автореф. дис... канд. филол. наук: 10.02.19. М., 1999. 25 с.

31. Фесенко Т.А. Этноментальный мир человека: опыт концептуального моделирования: автореф. дис. ... д-ра филол. наук. М., 1999. 52 с.

32. Философский энциклопедический словарь. Отв. ред. М.Н. Силин. М.: ТЕРРА, 1997. С. 350-355.

33. Фрумкина Р.М. Концептуальный анализ с точки зрения лингвиста и психолога // НТИ. Сер. 2. Информационные процессы и системы. Ежемесячный научно-технический сборник. 1992. № 3. С. 1-8.

34. Холодная М.А. Интегральные структуры понятийного мышления. Томск: Изд-во Томского госуниверситета, 1983. С. 20. 
35. Чернейко Л.0. Имя Судьба как объект концептуального и ассоциативного анализа // Вестник Московского университета. Серия 9. Филология. 1996. № 9. C. 20-30.

36. Dictionnare scientifique Francofon. Paris: Hachett Edicef, 1997. 1552-1555p.

37. Picht H. The Concept in Terminology a unit of thought? // Научно-техническая терминология. 2002. Вып. 2.7 р.

38. Smith V. Copenhagen working pagers in LSP. USA, 2000. $10 \mathrm{p}$.

( Т) Троцюк Светлана Николаевна (svetlana.trocuk@mail.ru).

Журнал «Современная наука: актуальные проблемы теории и практики»



